\section{Toxicity of Ethylene Glycol Vapors to Cucumbers}

\author{
Theodore W. Tibbitts \\ Department of Horticulture, University of Wisconsin-Madison, Madison, \\ WI 53706-1590
}

Barbara Peterson

Dynamac Corporation, Mail Code DYN-2, Kennedy Space Center, FL 32899

Additional index words. contaminants, coolants, closed environments

\begin{abstract}
Vapors of ethylene glycol, 1,2 ethanediol, were found to cause serious injury to cucumbers in controlled-environment rooms in which this chemical was utilized for heat transfer. A chlorotic injury, which later became necrotic, occurred at the leaf apices and progressed along the margins to cause stunting and cupping of the leaves. High concentrations caused cessation of shoot growth and produced florets with short petals and stunted sepals. The source of the contaminating vapors appeared to be residual ethylene glycol from leaks over the years that had impregnated the floors or walls of the rooms. Activated charcoal or potassium permanganate filters installed in the circulating air stream of the rooms effectively prevented injury.
\end{abstract}

Ethylene glycol, 1,2 ethanediol, is utilized for heat transfer in the cooling of plant growth units primarily in facilities where a central system distributes coolant to several different units. In the Biotron at the Univ. of Wisconsin, ethylene glycol is used for cooling all the controlled environment rooms and chambers utilized for plant and animal research. This article details a serious problem with growth of cucumbers (Cucumis sativus L.) in many of the rooms of this facility as a result of ethylene glycol contamination of the atmosphere.

Symptomatology. The injury occurs first at the apex and at the protruding points of the leaf blade as it emerges from the growing tip, and may progress all along the leaf margin and extend $1-3 \mathrm{~mm}$ into the leaf. The injured area is first chlorotic and later necrotic. This restricted growth at the leaf margin causes the margins to curl, and cupping occurs as the leaf continues to enlarge (Fig. 1).

When plants are grown in a room free of ethylene glycol and then moved into a contaminated room, symptoms begin to develop on the new developing leaves within $5 \mathrm{~d}$. Enlarged leaves seldom develop symptoms. Curling and stunting of young leaves reduces the growth rate of the plants. In one Biotron room with higher levels of contamination, fully developed leaves exhibited $1-3 \mathrm{~cm}$ diameter collapsed areas between the veins $24 \mathrm{~h}$

Received for publication 10 Aug. 1998. Accepted for publication 27 Oct. 1998. A special thanks to the staff of the Biotron, particularly Charles Baum and Arvid Lekies, for their help in scheduling rooms and maintaining plants for the separate tests that were undertaken. This research was supported by the College of Agricultural and Life Sciences, Univ. of Wisconsin-Madison, and by Dynamac Corp., Kennedy Space Center, Fla. The cost of publishing this paper was defrayed in part by the payment of page charges. Under postal regulations, this paper therefore must be hereby marked advertisement solely to indicate this fact. were induced by this mixture, reagent grade ethylene glycol was tested in the same way, and "typical" symptoms again appeared. By after transfer, and these collapsed areas later became necrotic. All new leaves at the apex of rets had short petals and small, stunted se

To determine if ethylene glycol was the causal agent, an open dish of the commercial coolant, which included inhibitors, was placed on the shelf of a small noncontaminated chamber beside healthy cucumber plants that had been varying the surface area, the variations in symptomatology found in the Biotron rooms were reproduced. When a large quantity of coolant was used, symptoms occurred on the enlarged leaves within $24 \mathrm{~h}$; when a smaller quantity was used, symptoms developed only after $5 \mathrm{~d}$ and only on the young developing leaves. Cultivars varied in sensitivity, but all exhibited injury and growth of all was reduced to unacceptable levels.

Filtering. The effects of the ethylene glycol were prevented by installation of activated charcoal or $\mathrm{KMnO}_{4}$ (Purafil) filters installed in the air handling system of each room. The problem was also alleviated in rooms where a water spray was utilized in the air handling system to provide very high humidity levels, provided the spray was continuous.

Source. The source of atmospheric contamination in the rooms is not known. There have been significant leaks from valves and fittings at different times over the years and the ethylene glycol may have permeated the concrete floors of the growing rooms or been adsorbed onto the fabric of the air handling ducts, resulting in a continuous, low level of contamination.

Concentrations. Several efforts to measure the concentrations of ethylene glycol in the air with mass spectroscopy and gas chromatography were unsuccessful. Ethylene glycol is very polar, whereas initial analyses were designed to detect nonpolar compounds. Other methods are currently being tested, including a trap technology in air preconcentrators to capture polar compounds. In addition, single ion monitoring for ethylene glycol could increase sensitivity to levels below $1 \mu \mathrm{g} \cdot \mathrm{L}^{-1}$. A detector tube containing a dry absorbent that

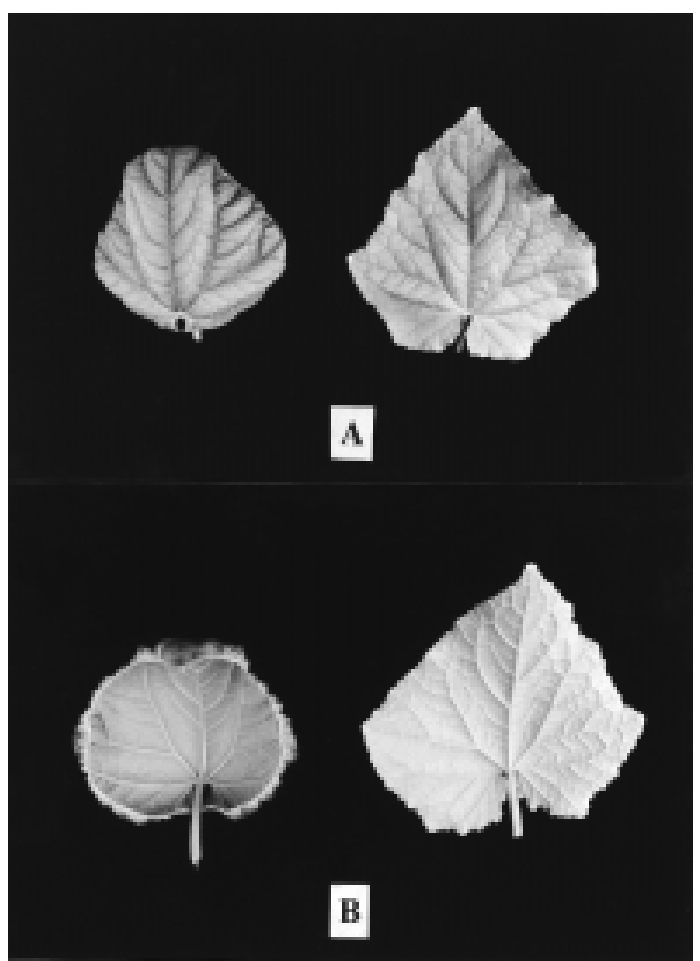

Fig.1. Cupping of cucumber leaf (left) as a result of ethylene glycol vapors. Normal leaf on right. (A) Upper surface. (B) Lower surface. 
changed color when ethylene glycol vapors were drawn through it was utilized to establish an approximate level of contamination. However, no color change was detectable when the prescribed volume of air, or even when 10 times the prescribed volume, was drawn through the column, indicating that the concentration of ethylene glycol in the contaminated rooms was below $10 \mu \mathrm{g} \cdot \mathrm{L}^{-1}$.

Implications. No other species of plants appear to have been injured by these low residual vapors of ethylene glycol in the Biotron rooms, although a necrotic spotting was observed on potatoes (Solanum tuberosum L.) held for several days in a room in which a quantity of ethylene glycol had leaked onto the floor. Nonetheless, the rooms and chambers have been fitted with filters to prevent any possible injury. Cucumbers are one of the most sensitive plants to air pollutants and to herbicides (Pezet and Gindrat, 1978; Staub and Knerr, 1991). Thus, the effects of ethylene glycol vapors on other plants may be more subtle, causing no obvious symptoms of injury, but possibly only a general stunting. Therefore, this problem requires additional study to determine if plant growth, and possibly flowering and subsequent seed set and fertility, may be influenced by ethylene glycol.

Similar injury was noted with a propylene glycol leak from an under-bench heating system in a greenhouse growth room at the Institute of Arctic Biology in Fairbanks, Alaska. Plant species that showed damage from propylene glycol vapors included Clerodendrum fragrans (Schauer), Aristolochia elegans
(Hassl.), Ochna multiflora (Kuntze), and Dalechampia heterobractea (Armbr.), D. jurana (Ule), D. aristolochiflia (Kunth), and D. fragrans (Armbr.) (Heather McIntyre, personal correspondence, 1997). Most species exhibited leaf necrosis and curling of the tips and margins, as noted with the ethylene glycol vapors, and some species also exhibited leaf abscission.

The injuries that are produced on young leaves by ethylene glycol and propylene glycol are very similar in appearance to calciumrelated injuries on terminal leaves (Barta and Tibbitts, 1986; Marschner, 1983). The glycols may reduce calcium movement to young leaves by limiting transpirational water movement either through a direct influence on the water transport process or on the development and opening of stomata and hydathodes.

The toxicity of ethylene glycol may be especially significant for plants used in space research and future space bases because of the widespread use of this coolant in these tightly closed systems, and it is a concern for plant experiments conducted on the MIR station, for ethylene glycol leaks have been reported in recent years. Care should be taken to isolate plant growing areas from the coolant systems as much as possible, and/or to carefully filter air passing over plants, to insure healthy plant growth in any closed environment.

Thus ethylene glycol, and possibly propylene glycol, compounds that generally do not pose problems to plants in an open environment, should be added to the list of contaminants that occasionally injure plants growing in closed environments. This list currently includes ethylene, mercury vapors, dibutyl phthalate, cyclohexylamines, and paint vapors (Hardwick et al., 1984; Pezet and Gindrat, 1978; Tibbitts, 1997; Waldron and Terry, 1975; Wheeler et al., 1996).

\section{Literature Cited}

Barta, D.J. and T.W. Tibbitts. 1986. Effects of artificial enclosure of young lettuce leaves on tipburn incidence and leaf calcium concentration. J. Amer. Soc. Hort. Sci. 111:413-415,

Hardwick, R.C., R.A. Cole, and R.P. Fyfield. 1984 Injury to and death of cabbage (Brassica oleracea) seedlings caused by vapors of dibutyl phthalate emitted from certain plastics. Ann. Appl. Biol. 105:97-105

Marschner, H. 1983. General introduction to the mineral nutrition of plants, p. 5-60. In: A. Lauchli and R.L. Bielski (eds.). Encyclopedia of plant physiology. Inorganic plant nutrition. vol. 15A. Springer Verlag, New York.

Pezet, R. and D. Gindrat. 1978. Injury to plants caused by cyclohexylamine vapors from silicone rubber in growth chambers. Plant Dis. Rptr. 62:101-104.

Staub, J.E. and L.D. Knerr. 1991. Evaluations and correlated responses for resistance to chloramben herbicide in cucumber. HortScience 26:905908.

Tibbitts,T. W. 1997. Air contaminants, p. 81-86. In: R.W. Langhans and T.W. Tibbitts (eds.). 1997. Plant growth chamber handbook. North Central Regional Publ. 340. Iowa State Univ., Ames.

Waldron, L.J. and N. Terry. 1975. Effect of mercury vapor on sugar beets. J. Environ. Qual. 4:58-60.

Wheeler, R.M., B.V.Peterson, J.C. Sager, and W.M Knott. 1996. Ethylene production by plants in a closed environment. Adv. SpaceRes. 18(4/5):193196. 